\title{
ENTOMOLOGY
}

\section{Efficacy of chlorpyrifos and fipronil in relation to soil depths against subterranean termites}

\author{
S. Ahmed, ${ }^{1}$ B. Hassan, ${ }^{1}$ M.M. Yaqoob, ${ }^{1}$ M.S. Nisar, ${ }^{2}$ A. Rashid $^{3}$ \\ ${ }^{1}$ Department of Entomology, University of Agriculture, Faisalabad; ${ }^{2}$ University College of Agriculture, Ghazi University, \\ DG Khan; ${ }^{3}$ ORIC, University of Agriculture, Faisalabad, Pakistan
}

\begin{abstract}
The present studies aimed at finding the best concentration of chlorpyrifos and fipronil following mixing with the same and different soil depths in laboratory and field trials. Barrier efficacy of these insecticides was measured by determining wood weight loss kept as bait on the treated soils in the field experiment and length of galleries in the laboratory experiments. Results showed that termites were able to penetrate galleries treated with both insecticides at variable distances. Length of gallery and repellence was concentration dependent. Five percent concentration of both insecticides at $45 \mathrm{~cm}$ was the best treatment in comparison with other combination of concentration and soil depths. Maximum gallery length and repellence was observed after the application of chlorpyrifos in comparison with fipronil. Fipronil applied at different concentrations following mixing with the same and with different soil depths was the best treatment as a standard pre-construction step.
\end{abstract}

Correspondence: Babar Hassan, Termite Management Laboratory, Department of Entomology, University of Agriculture, Agriculture University Road, Faisalabad 38000, Pakistan.

Tel.: +92.3377105236

E-mail: sialuaf@gmail.com

Key words: penetration; termiticides; soil barrier; repellent.

Contributions: the authors contributed equally.

Conflict of interest: the authors declare no potential conflict of interest.

Received for publication: 12 November 2016.

Revision received: 30 December 2016.

Accepted for publication: 13 January 2017.

(C) Copyright S. Ahmed et al., 2017

Licensee PAGEPress, Italy

Journal of Entomological and Acarological Research 2017; 49:6386

doi:10.4081/jear.2017.6386

This article is distributed under the terms of the Creative Commons Attribution Noncommercial License (by-nc 4.0) which permits any noncommercial use, distribution, and reproduction in any medium, provided the original author(s) and source are credited.

\section{Introduction}

The most troublesome termites in Pakistan are the fungusgrowing termites such as Odontotermes spp. Microtermes spp. Heterotermes indicola Wasmann and Coptotermes heimi (Wasmann) exploit the soils for foraging by making tunnels and in this way cause nutrient recycling (Ahmed et al., 2006); in this process they cause considerable losses to crops, trees and wooden work in buildings (Ahmed \& Qasim, 2011). To protect woods in the buildings, chemical barrier is as appropriate and effective today as these were 50 years ago (Gold et al., 1994; 1996). Soil termiticides that are used for this purpose may also require reapplication to maintain protection of structures ( $\mathrm{Su}$ et al., 1993). Non-repellent compounds are desired for soil treatment because they do not appear to disturb termite scavenging in the treated soil area and have a late mode of action that may contribute to transferring of the active ingredient in the colony through trophallaxis and social grooming (Kard, 2003).

Chemical barrier is dependent upon various factors such as soil types and their composition (Grace et al., 1993; Smith \& Rust, 1993; Forschler, 1994), coverage of chemical treated soil (Su et al., 1993) and depth of penetration of termiticides (Gold et al., 1996). Acidic soil with low clay and organic content were most favourable for stability of termiticides than alkaline soil with high clay and organic contents. Repellency of isoborneol decreased with increasing clay content and particle size in treated soil (Blaske et al., 2003). Imidacloprid showed non-significant difference of its efficacy in soil types like sandy loam and silty clay loam, but termiticide quantity increased with depth from injection point (Davis \& Kamble, 2008). Higher application rates of imidacloprid, fipronil and bifenthrin in loamy soil resulted in greater availability of these termiticides (Saran \& Kamble, 2008). Concentration and treatment thickness significantly affected both mortality and penetration by $R$. flavipes into imidacloprid-treated soil (Gahlhoff \& Koehler, 2001). R. flavipes and Coptotermes formosanus Shiraki penetrated 20-mm treatments of all tested fipronil concentrations, as well as $50 \mathrm{~mm}$ soil treated with fipronil at $<10 \mathrm{ppm}$. Termites tunnelled less at low concentration into 50-mm treated soil (Hu, 2005). Penetration of imidacloprid and fipronil was not only based on soil type but also on moisture and organic matter contents and depths of soil (Peterson, 2009). A latest formulation of fipronil dust was ineffective at greater depth of soil and was active only on top soil core (Gautam et al., 2012). Temporal changes in indoxacarb and chlorantraniliprole residues in four Midwestern soils following field applications of 
indoxacarb (0.0625 and $0.125 \%)$ and chlorantraniliprole (0.05 and $0.10 \%$ ) showed no differences with soil type or depth (Spomer \& Kamble, 2011). Residues of pyrethroid (permethrin) liquid formulations reduced with soil depth (Kard et al., 2014). Fipronil as non-repellent termiticide has been used in building foundations against subterranean termites (Potter \& Hillery, 2001; Ying \& Kookana, 2006; Rawat, 2012). Chlorpyrifos as repellent termiticide has been used as soil barrier and is currently all over the world (Gatti et al., 2002). Chlorpyrifos and fipronil concentrations at lower depths were little changed after 15 months from the time of treatment but there was a major reduction in imidacloprid concentration at all depths (Horwood, 2007). Fipronil and its metabolites dissipated slowly in deeper layers with time and after 56 months of treatment residues were detected only up to $30 \mathrm{~cm}$ depth (Sharma et al., 2008).

In the present study, two classes of termiticides, chlorpyrifos and fipronil were applied at different concentrations following mixing with same and different soil depths in the laboratory and field as a standard pre-construction step.

\section{Materials and methods}

Assorted workers of the termite species were collected from bait stations placed in the form of PVC pipes of 0.46-0.69 m vertically in such a way that $1-2 \mathrm{~cm}$ of the pipes remained above the ground having a roll of moist corrugated cardboards inside on fortnightly basis at Post Agriculture Research Station (PARS) area of University of Agriculture, Faisalabad, Pakistan. Soil for bioassays was sampled from same place. The soils were sieved for the pulverizing fine particles to avoid from clotting after the removal of debris. In field experiments, poplar wood (Populus deltoides) (susceptible to termites) of $5 \times 3 \times 2 \mathrm{~cm}$ dimension was used as indicator of damage after termiticide application in soils. Chlorpyrifos (Helmet@40 EC) and fipronil (Detector@5 SC) in 0.05, 0.1, 0.25 , and $0.5 \%$ concentrations were used in bioassays.

\section{Laboratory bioassays}

\section{Barrier efficacy of different concentrations of chlorpyrifos and fipronil in same soil core thickness against termite workers}

Plastic trays having $4 \mathrm{~cm}$ soil mixed with each of $0.05,0.1$, 0.25 , and $0.5 \%$ concentrations of chlorpyrifos and fipronil were arranged in CRD with three replications. Soil moistened only with water was spread in one tray as control treatment. Moistened filter paper was also placed in the trays. 100 workers of termites with 10 soldiers were released in the plastic trays to determine mortality after 12 days. Galleries formed during this period were also measured while seeing from bottom of trays. For the repellency test, plastic trays had two equal parts of soil one with each of four concentration of chlorpyrifos and fipronil and other half had soil treated with water only as control treatment. 100 workers of termites with 10 soldiers were released in the middle of trays and termites settled on any part were counted after 12 hours.

\section{Barrier efficacy of chlorpyrifos and fipronil in different soil core thickness against termites}

Most effective concentration from experiment No. 1 was mixed with different soil thickness in plastic trays and soil thickness was 2 , 4,6 and $8 \mathrm{~cm}$. In control treatment, soils of different thickness were moistened with water only. Mortality, galleries length and repellence were measured as described in experiment No. 1.

\section{Field studies}

\section{Barrier efficacy of different concentrations of chlorpyrifos and fipronil in same soil depth against termites}

A piece of land of $3.6 \times 2.4 \mathrm{~m}$ dimension with very high termites infestation was selected and divided into twenty five equal size sub plots of $0.6 \times 0.3 \mathrm{~m}$ dimension. A soil core of $15 \mathrm{~cm}$ depth was dug out from each sub-plot and the soil core from each subplot was treated with $0.05,0.10,0.25$ and $0.5 \%$ concentrations of chlorpyrifos and fipronil. After the treatment, soil cores were replaced in respective sub-plot in $2 \times 2$ factorial $\mathrm{RCBD}$ with three replications. The control with untreated soil core (water mixed) was also included. Three pieces of Populus deltoides wood $(2 \times 3 \times 5$ $\mathrm{cm})$ were also placed on each sub-plot. Percent weight losses of these wood pieces were determined 8 weeks after treatment.

\section{Barrier efficacy of chlorpyrifos and fipronil in different depths of soil against termites}

Set up of this experiment was same as the above field experiment except that soil cores of different depths i.e. 15, 30, 45 and 60 $\mathrm{cm}$ were dug out and treated with $0.5 \%$ of chlorpyrifos and fipronil.

\section{Statistical analysis}

Laboratory trials were arranged in Completely Randomized Design (CRD) while for field trails all treatments were arranged in $2 \times 2$ factorial RCBD. Analysis of variance was performed and significantly different means were separated by Tukey HSD test. All analyses were conducted using the statistical package Minitab 17. The significance level was $\mathrm{P}<0.05$

\section{Results}

Mortality of termites in laboratory assay was concentrations dependent. For length of galleries and mortality of termites, fipronil performed non-significantly different at 0.25 and $0.5 \%$ concentrations, while chlorpyrifos performed significantly different at each concentrations for both termite mortality and galleries length. Termites showed $10 \%$ mortality in control treatment. Mortality was significantly high in fipronil treated soil as compared to chlorpyrifos (Figure 1A). Length of gallery by termite workers decreased with increase in concentrations of both insecticides. Galleries were significantly longer in chlorpyrifos treated soil than fipronil ones in numerical terms (Figure 1B).

Soil core depth had significant effect on survivability of termite workers. Mortality decreased with increase in depth of soil core. At the lowest core depth, both insecticides imparted non-significant mortality. In other soil depths, chlorpyrifos had significant less mortality than fipronil (Figure 2A). On the other hand, length of galleries varied significantly with depths. Galleries were longer in chlorpyrifos treated soil as compared to fipronil treated soil (Figure 2B). Repellency data showed significant difference in context of soil depths. Chlorpyrifos up to $6 \mathrm{~cm}$ depth was significantly different from other depths and the insecticide except at $4 \mathrm{~cm}$ with fipronil (Figure 2C).

Weight loss of bait kept on the surface of same soil core treated with different concentrations of insecticides showed non-significant difference at 0.1 and $0.25 \%$ concentrations but was significantly different from control treatment. Weight loss at $0.5 \%$ concentration of fipronil was significantly different from that at $0.05 \%$ of fipronil and chlorpyrifos (Figure 3A). Weight loss at all soil 
depths having same concentrations of both the insecticides had non-significant difference among one another. Control treatment at all depths had significant difference with treated soil cores of different depths (Figure 3B).

\section{Discussion and conclusions}

In the present studies, mortality of termites was affected by soil depth but weight loss of wood has shown non-significant difference at various depths. It is well known that barrier efficacy of termiticides are affected by soil factors such as types, various biotic components, population density of subterranean termite colonies and depth of treatments (Grace et al., 1993; Smith \& Rust, 1993; Forschler, 1994; Neoh et al., 2012). Ahmed and Qasim (2011) conducted a study on termites foraging/scavenging activity towards a
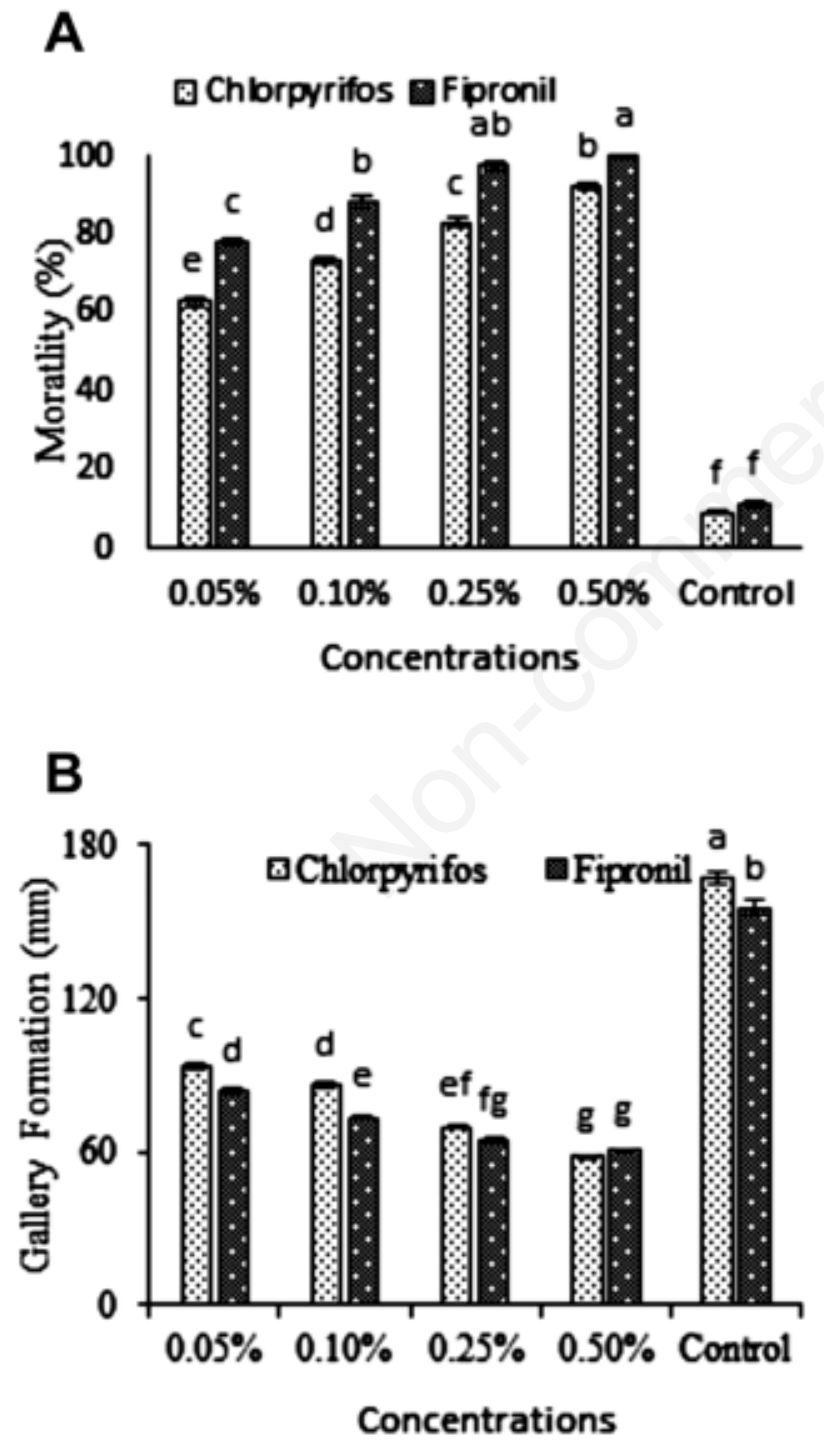

Figure 1. Comparison of termites' mortality (\%) (A) and tunnel length $(\mathrm{mm})(\mathrm{B})$ after 12 days of exposure in treated soils with different doses of chlorpyrifos and fipronil. farm building and efficacy of soil barrier inside this farm building. They installed PVC pipes grooved with cardboard around the building to lead the termites to the wood stakes inside a soil pit. Chlorpyrifos, imidacloprid, bifenthrin and alphacypermethrin were used as soil barrier around this pit in swath band of $0.32 \mathrm{~m}$ wide and $0.4 \mathrm{~m}$ deep. The most effective termiticides were chlorpyrifos and alpha cypermethrin against termites. Interaction of concentrations and depths has shown non-significant difference between chlorpyrifos and fipronil. Generally, chlorpyrifos is considered repellent termiticide, however, termites penetrated not only in the soil treated

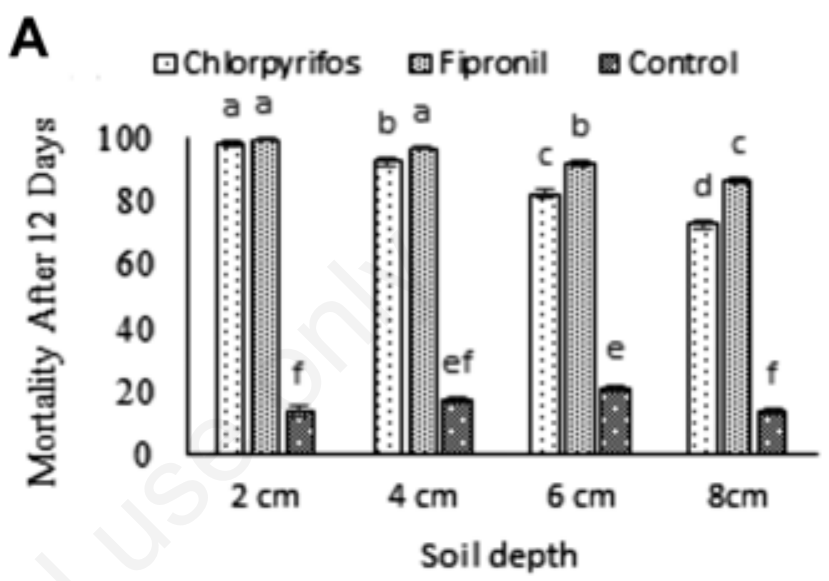

B
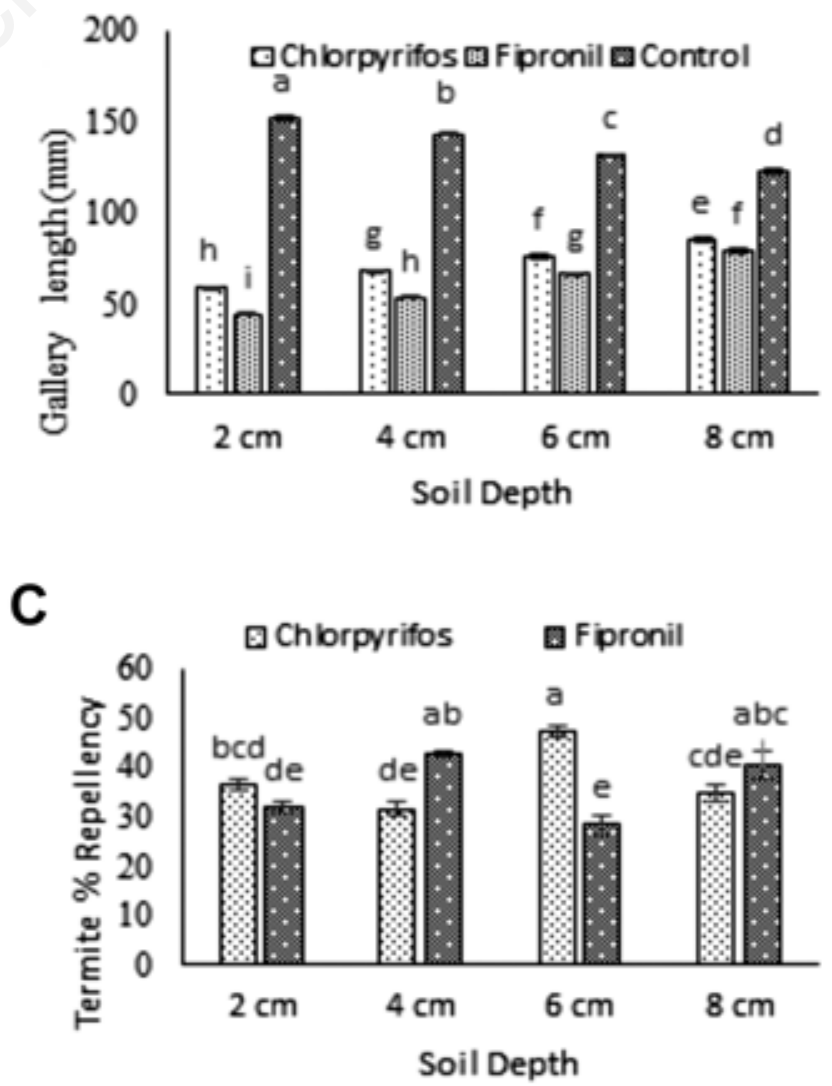

Figure 2. Comparison of (A) termites' mortality, (B) gallery formation $(\mathrm{mm})$ after 9 days and $(\mathrm{C})$ repellency after 24 hours of exposure to insecticides in different depths of soil. 
with it in the present studies but has also been reported elsewhere (Smith \& Rust, 1993). Forschler (1994) studied soil barrier by mixing different concentrations of isofenphos, chlorpyrifos, fenvalerate, permethrin and cypermethrin with sand and checking survivor and tunnel formation. Isofenphos, and chlorpyrifos were effective against termites. Eastern subterranean termites, $R$. flavipes penetrated various concentrations and treatment thicknesses ranging from 1.0 to $50.0 \mathrm{~mm}$ of Dursban TC and Premise 75 in a laboratory bioassay. Termites penetrated only a few millimeters into $500 \mathrm{ppm}$ Dursban TC-treated soil at all thicknesses but increased penetration as concentrations decreased (Gahlhoff \& Koehler, 2001). Penetration of termites into chlorpyrifos treated soil depended upon concentration and depth of treatment; required longer time after initially failed to make tunnel (Dupo \& Dupo, 2003).

Firponil resisted penetration of Heterotermes aureus for one application in gravel as compared to the native soil (Baker \& Weeks, 2002). R. flavipes and C. formosanus totally penetrated 20$\mathrm{mm}$ treatments of all tested fipronil concentrations, as well as 50 $\mathrm{mm}$ soil treated with fipronil at $<10 \mathrm{ppm}$. At 50 and $100 \mathrm{ppm}$ of fipronil, termites tunneled only a mean of 87 and $47 \mathrm{~mm}$ deep into $50-\mathrm{mm}$ treated soil, respectively. Imidacloprid also provided termites' barrier up to $1.22 \mathrm{~m}$ to protect building foundations (Davis \& Kamble, 2008). Penetration of fipronil was up to $60 \mathrm{~cm}$ initially but after 56 months $30 \mathrm{~cm}$ was the depth where residues could be found (Sharma et al., 2008). This is not in agreement with the present results in which fipronil not only allowed the termites to make tunnel but also appeared to be dependent upon soil type and depth of penetration as reported elsewhere (Gautam et al., 2012). Soils with low organic matter contents were favorable for termiticide barrier (Peterson, 2009; 2010). Based on data of this study it was found that $5 \%$ of chlorpyrifos and fipronil up to $45 \mathrm{~cm}$ depth of soil were effective barrier as preconstruction step. But in comparison of both insecticides fipronil performed well in killing termites and reducing galleries length as compare to chlorpyrifos. So preference should be given to this insecticide for barrier as preconstruction step.

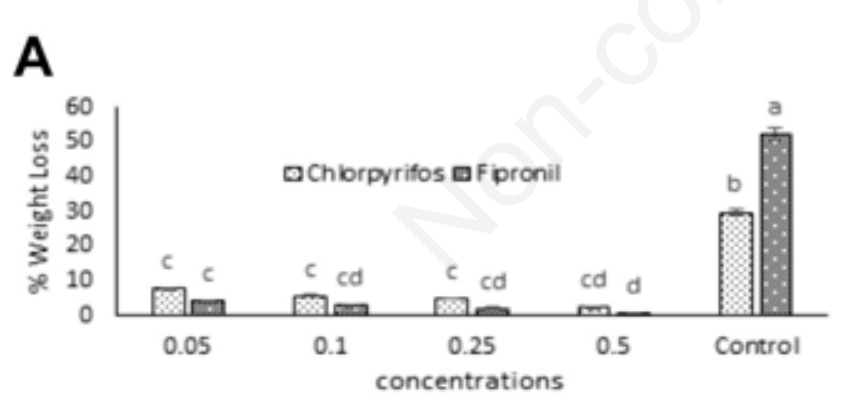

B

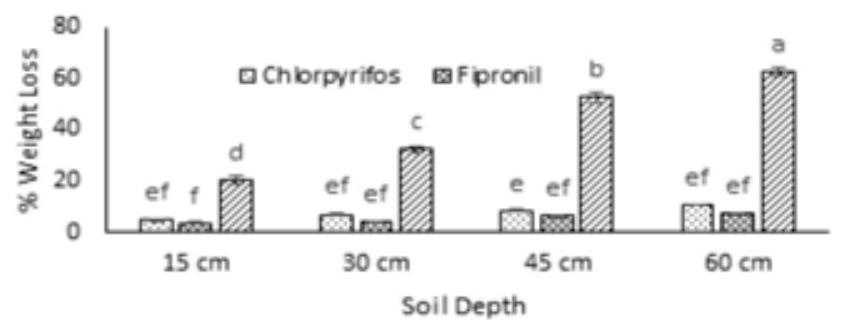

Figure 3. Comparison percent weight loss of wood due to termites' attack after 8 weeks of exposure to soils treated with different concentrations of chlorpyrifos and fipronil (A) at different soil depths (B).

\section{References}

AHMED S., QASIM M., 2011 - Foraging and chemical control of subterranean termites in a farm building at Faisalabad, Pakistan. - Pak. J. Life Soc. Sci. 9: 58-62.

AHMED S., MUSTAFA T., RIAZ M.A., HUSSAIN A., 2006 Efficacy of insecticides against subterranean termites in sugarcane. - Int. J. Agri. Biol. 8: 508-510.

BAKER P.B., WEEKS B.E., 2002 - Barrier efficacy of organophosphate, pyrethroid, phenylpyrazol and chloronicotinyl formulations against Heterotermes aureus (Isoptera: Rhinotermitidae). - In: Jones, S.C., J. Zhai and W.H. Robinson, (eds.), pp. 369-374. $4^{\text {th }}$ Intern. Conf, Urban Pests. Pocahontas Press, Blacksburg, VA.

BLASKE V.U., HERTEL H., FORSCHLER B.T., 2003 - Repellent effects of isoborneol on subterranean termites (Isoptera: Rhinotermitidae) in soils of different composition. - J. Econ. Entomol. 96: 1267-1274.

DAVIS R.W., KAMBLE S.T., 2008 - Effect of rod tips and soil types on the distribution of imidacloprid and a water soluble dye following subsoil rodding application for subterranean termite control (Isoptera: Rhinotermitidae). - Sociobiol. 51: 437-460.

DUPO SR H.C., DUPO JR H.B., 2003 - Bioefficacy of Bifenthrin $10 \mathrm{TC}$ as soil barrier treatment against subterranean termites. Philipp. Entomol. 17: 188-192.

FORSCHLER B.T., 1994 - Survivorship and tunneling activity of Reticulitermes flavipes (Kollar) (Isoptera: Rhinotermitidae) in response to termiticides soil barriers with and without untreated soil. - J. Entomol. Sci. 29: 43-54.

GAHLHOFF J.R., KOEHLER P.G., 2001 - Penetration of the eastern subterranean termite into soil treated at various thicknesses and concentrations of Dursban TC and Premise 75. - J. Econ. Entomol. 94: 86-91.

GATTI S.S., HENDERSO G., ABDEL-AAL, Y.A.I., IBRAHIM S.A., 2002. - Acetylcholine esterase mediated susceptibility of soldiers and workers of Formosan subterranean termite (Isoptera: Rhinotermitidae) to chlorpyrifos. - J. Econ. Entomol. 95: 813-819.

GAUTAM B.K., HENDERSON G., DAVIS R.W., 2012 - Toxicity and horizontal transfer of $0.5 \%$ fipronil dust against Formosan subterranean termites. - J. Econ. Entomol. 105: 1766-1772.

GOLD R.E., COLLINS A.A., PAWSON B.M., HOWELL H.N., 1994 - Termiticide technology-the isofenphos dilemma. Technology. - J. Frankl. Inst. 331: 19-198.

GOLD R.E., HOWELL H.N., PAWSON B.M., WRIGHT M.S., LUTZ J.C., 1996 - Persistence and bioavailability of termiticides to subterranean termites (Isoptera: Rhinotermitidae) from five soil types and locations in Texas. - Soc. Biol. 28: 337-363.

GRACE J.K., YATES J.R., TAMASHIRO M., YAMAMOTO R.T., 1993 - Persistence of organochlorine insecticides for Formosan subterranean termite (Isoptera: Rhinotermitidae) control in Hawaii. - J. Econ. Entomol. 6: 761-766.

HORWOOD M. A., 2007 - Rapid degradation of termiticides under field conditions. - Austr. J. Ento. 46: 75-78.

HU X.P., 2005 - Evaluation of efficacy and non-repellency of indoxacarb and fipronil-treated soil at various concentrations and thicknesses against two subterranean termites (Isoptera: Rhinotermitidae). - J. Econ. Entomol. 98: 509-517.

KARD B.M., 2003 - Integrated pest management of subterranean termites (Isoptera). - J. Entomol. Sci. 38: 200-224.

KARD B., TOMPKINS G., ROTRAMEL G., Renello L., 2014 Dispersion of standard and cellulose-augmented termiticides 
in 'ABC 'gravel foundation fill. - J. Kansas Entomol. Soci. 87: 205-218.

NEOH K.B., HU J., YEOH B.H., LEE C.Y., 2012 - Toxicity and horizontal transfer of chlorantraniliprole against the Asian subterranean termite Coptotermes gestroi (Wasmann): effects of donor: recipient ratio, exposure duration and soil type. - Pest Manag. Sci. 68: 749-756.

PETERSON C.J., 2009 - Depth of initial penetration of two aqueous termiticide formulations as a function of soil type and soil moisture. ACS symposium series. Oxford University Press: 97-106 pp.

PETERSON C.J., 2010 - Varying termiticide application rate and volume affect initial soil penetration. - J. Econ. Entomol. 103: 433-436.

POTTER M.F., HILLERY A.E., 2001 - Thinking "outside" the box. - Pest Contr. Technol. 29: 68-84.

RAWAT B., 2012 - Effectiveness of fipronil 2.5EC for termite management in building. - Pestol. 38: 19-24.

SARAN R.K., KAMBLE S.T., 2008 - Concentration-dependent degradation of three termiticides in soil under laboratory con- ditions and their bioavailability to eastern subterranean termites (Isoptera: Rhinotermitidae). - J. Econ. Entomol. 101: 1373-1383.

SHARMA K., SHARMA V., GUPTA P., JAYA M., KUMAR A., SINGH B., 2008 - Persistence and vertical distribution of termiticide fipronil in modified ground board test. - Environ. Monit. Assess. 137: 179-184.

SMITH J.L., RUST M.K., 1993 - Cellulose and clay in sand affects termiticide treatments. - J. Econ. Entomol. 86: 53-60.

SPOMER N.A., KAMBLE S.T., 2011 - Temporal changes in chlorantraniliprole and indoxacarb in four Midwestern soils and bio-efficacy against the eastern subterranean termite (Isoptera: Rhinotermitidae). - J. Econ. Entomol. 104: 990-1001.

SU N.Y., SCHEFFRAHN R.H., BAN P.M., 1993 - Barrier efficacy of pyrethroid and organophosate formulations against subterranean termites (Isoptera: Rhinotermidae). - J. Econ. Entomol. 86: $772-776$.

YING G.G., KOOKANA R.S., 2006 - Persistence and movement of fipronil termiticide with under slab and trenching treatments. - Environ. Toxicol. Chem. 25: 2045-2050. 